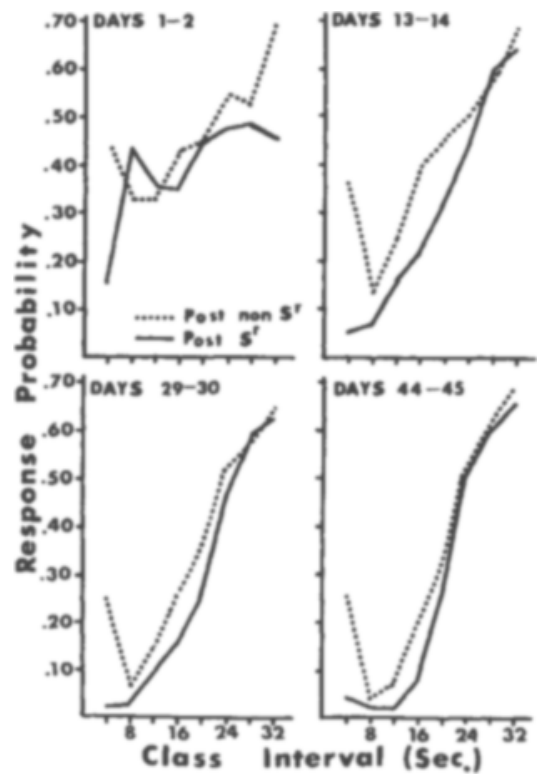

Fig. 2. Development of post $S^{R}$ and post non-SR IRT/Opportunity distributions across 45 training sessions. The data are plotted at the upper limit of the class interval.

were used. Following the 45 training sessions all Ss were allowed 2 days of ad lib feeding, then anesthetized with Nembutal and given bilateral lesions of the septal nuclei. The lesions were created by passing 1.5-mA anodal dc for $20 \mathrm{sec}$ through the uninsulated tip of a stereotaxically guided stainless-steel electrode. Coordinates were $1.5 \mathrm{~mm} \mathrm{~A}, .5 \mathrm{~mm} \mathrm{~L}$, and $6.0 \mathrm{~mm} \mathrm{D}$, with respect to the bregma, and with the head at a 5-deg angle to a horizontal plane. After surgery 30,000 units of Bicillin were administered.

Postoperatively Ss were allowed 3 days of ad lib feeding, followed by 3 days of readjustment to the deprivation schedule. After 12 daily test sessions on the DRL 20 -sec schedule they were anesthetized with an overdose of Nembutal and perfused with saline and formalin. The brains were removed, fixed in acid formalin, dehydrated in pyridine, embedded in celloidin, and sectioned at $15 \mathrm{~m} \mu$. Sections throughout the lesion were stained with cresyl violet and Luxol fast blue MBS

\section{Results and Discussion}

The lesions were similar to many previously described in the literature. Damage started anterior to the genu of the corpus callosum and extended posteriorly to the columns of the formix. In all Ss the lateral and medial septal nuclei were destroyed, but some supracommissural septal tissue remained intact.

The pre- and postoperative IRT/Opportunity results are presented in Fig. 3. They are based on all Ss and averages of 6 and 12 sessions, respectively. Postoperatively all Ss were deficient in inhibiting short- and medium-latency responses, with the response probability increasing with the time since a previous response. The effects were more marked for the post-non-SR component, suggesting that the cue value of $S R$ partially counters the lesion-induced effects.

Comparison of response probabilities using the Walsh test indicated that the response probabilities for the $4-8 \mathrm{sec}$, 8-12 sec, $12-16 \mathrm{sec}$, and $16-20 \mathrm{sec}$ intervals were significantly greater in their magnitude of change for the post-non- $S^{R}$ distributions $(p<.062)$. Similar results were found for percentage of reinforced responses. In all Ss the decreases were greater for the postnon-SR component. Of interest is the slight decrease in the number of $0.4 \mathrm{sec}$ latency post-non- $S^{R}$ responses following the lesions. If such responding reflects frustrative behavior, their decrease in frequency following lesions would suggest that affective changes are not responsible for the observed deficit.

The results suggest that a significant portion of the septal deficit in DRL responding results from a disruption of ritualized mediating behavior between responses and not disinhibition of lever pressing entirely. Such a deficit might include the omission of particular behavioral sequences or a tendency to terminate such sequences prematurely.

\section{REFERENCES}

ANGER, D. The dependence of in terresponse times upon the relative reinforcement of different interresponse times. Journal of Experimental Psychology, 1956, 52, 145-161. BURKETT, E. E., \& BUNNELL, B. N. Septal lesions and the retention of DRL performance in the rat. Journal of Comparative \& Phy siological Psychology, 1966, 62, 468-471. CARTER, D. E., \& BRUNO, L. J. J. On the discriminative function of the reinforcing stimulus. Psychonomic Science, 1968, 11, 21-22.

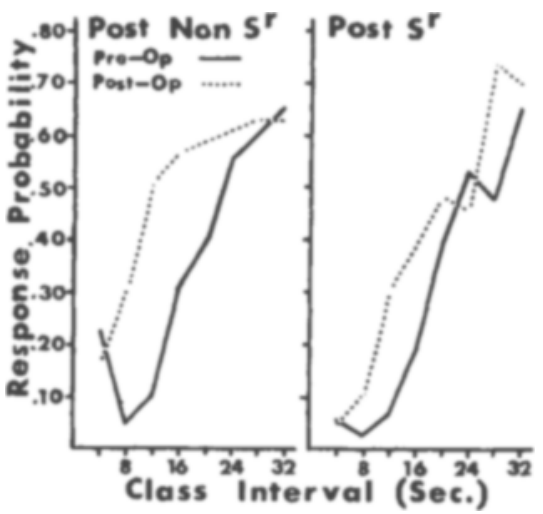

Fig. 3. Postoperative changes in post $\mathbf{S}^{R}$ and post non-SR IRT/Opportunity curves following septal lesions. The data are plotted at the upper limit of the class interval.

FARMER, J., \& SCHOENFELD, W. N. Effects of a DRL contingency added to a fixed-interval reinforcement schedule. Journal of the Experimental Analysis of Behavior, 1964, 7, 391-399.

FERRARO, D. P., SCHOENFELD, W. N., \& SNAPPER, A. G. Sequential effects in the white rat during conditioning and extinction on a DRL schedule. Journal of the Experimental Analysis of Behavior, 1965, 8, 255-260.

MacDOUGALL, J. M., VAN HOESEN, G. W., \& MITCHELL, J.C. The anatomical organization of septal projections in the maintenance of DRL behavior in rats. Journal of Comparative \& Physiological Psychology, in press.

MoCLEARY, R. A. Response modulating functions of the limbic system: Initiation and suppression. In F. Stellar and J. Sprague (Eds.), Progress in physiological psychology. New York: Academic Press, 1966.

SIEGEL, S. Nonparametric statistics for the behavioral sciences. New York: McGraw-Hill, 1956.

\section{NOTES}

1. This research was conducted while the first author was an NIGMS and the second author a NASA predoctoral trainee. Additional support was provided by Biomedical Sciences Support Grant FR-07036 from the General Research Support Branch, Division of Research Resources, NIH.

2. Now at Florida Presbyterian College, St. Petersburg, Florida 33733.

\title{
Stimulus compounding with an instrumental avoidance response
}

\section{LAURENCE MILLER, ${ }^{1}$ Western Washing- ton State College, Bellingham, Wash. 98225}

A light and buzzer each separately maintained a latency of response which avoided shock in a shuttle box. When the light and buzzer were compounded, the latency was significantly shorter than the latency to either single stimulus. This result reliably occurred only with Ss that had a high percentage of avoidance responses and fairly. short latencies to the single stimuli. The results were interpreted in terms of summation of response tendencies.

When two conditioned stimuli, each capable of maintaining a response, are 


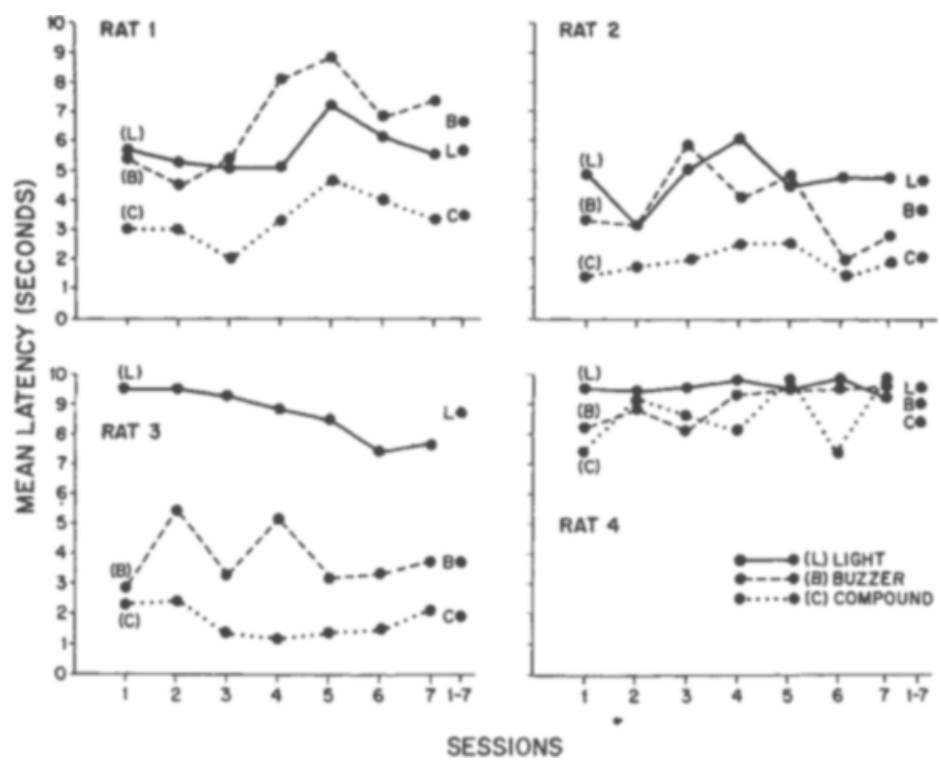

combined, their compound produces a greater magnitude or rate of response than either stimulus alone. This summation of response tendencies has been demonstrated in classical (Hull, 1940; Grings \& O'Donnell, 1956) and free-operant (Wolf, 1963; Weiss, 1964) conditioning.

The present experiment is an extension of compounding-summation to an instrumental avoidance response. If two stimuli, each maintaining a latency of avoidance responding, are combined, summation of response tendencies would predict that the latency produced by the compound be less than the latency maintained by either single stimulus.

\section{PROCEDURE}

The Ss were five male albino rats, 100 days old and maintained on ad lib food and water. The apparatus was a $22 \times 18 \times$ 12 in. flat black plywood shuttlebox with a grid floor of $1 / 8$-in. steel rods spaced $1 / 2$ in. apart. The stimuli, a $25-\mathrm{W}$ lightbulb and a Potter and Brumfield BU $120 \mathrm{~V}$ buzzer, were positioned at the midline of the box, the light 9 in. from the floor on the inside rear wall, and the buzzer on a platform outside the box 6 in. away from the rear wall. The shock source was a GrasonStadler shock generator. Latencies were measured with a Stoelting electric timer, accurate to $.01 \mathrm{sec}$.

Subjects were run in a two-way avoidance situation. Either a light or buzzer was presented on each trial. If $S$ crossed the midline to the other side before $10 \mathrm{sec}$, it avoided shock, and the light or buzzer was terminated. If $\mathrm{S}$ did not cross within $10 \mathrm{sec}$, shock was presented until $S$ moved to the other side, whereupon both shock and stimulus terminated simultaneously. The same procedure was repeated when $S$ was on the other side. Latency, the time from stimulus onset until $S$ crossed the midline, was measured. If $\mathbf{S}$ did not cross within $10 \mathrm{sec}$, the latency was recorded as $10 \mathrm{sec}$. Shock was applied to the side $\mathrm{S}$ had just left during the 60 -sec intertrial interval to prevent premature crossings. Ss were given 20 trials to each stimulus each day. The order of light and buzzer presentation was randomly determined. Shock intensity for each $S$ was adjusted to produce a mean latency of avoidance responding to each stimulus as near to a range of $4-7 \mathrm{sec}$ as possible. Intensity varied from .16-.60 mA.

After 8 days Ss 1-3 had attained, in each session, both the desired latency and a high percentage of avoidance responses to each stimulus. The per cent avoidance to the light and buzzer, respectively, was $90-100 \%$ for Ss 1 and 2 and 60 and $90 \%$ for S 3. For S 4 the percentages were $25-35 \%$, with latency from $8-9$ sec. $S 5$ never leamed to avoid, only to escape.

For testing, the 40 trials were divided into five blocks of eight trials. Light and buzzer were compounded once each block. The compound trial was randomly determined. Seven sessions of testing, one session each day, were conducted. S 5 was tested for only three sessions. Thus, Ss 14 each had five compound tests in each session, for a total of 35 tests over the seven test sessions.

\section{RESULTS AND DISCUSSION}

The results of the seven tests for Ss 14 are presented in Fig. 1. The mean latency of the five compound tests each session is plotted against the means of the light and buzzer. At the right of each graph are the mean latencies from pooling the data from the seven test sessions. The mean latencies to single stimuli and compound for $S 5$ were all $10 \mathrm{sec}$. A treatment by Ss analysis of
Fig. 1. Mean Iatencies of avoidance to single stimuli and their compound.

variance of each S's data revealed a significant difference due to stimulus condition $(p<.01)$ for Ss 1,2 , and 3. For $\mathrm{S} 4, \mathrm{p}=.07$, and for $\mathrm{S} 5, \mathrm{p}>.25$. A Newman-Keuls post hoc comparison of the treatment means for Ss 1-3 revealed that the latency produced by the compound was significantly shorter than the latency to either light or buzzer alone. For Ss 1 and 2, $p<.01$; for $S 3, p<.01$ for the compound vs light comparison and $p<.05$ for the compound vs buzzer comparison.

The data support a summation-ofresponse-tendencies interpretation. When two stimuli, each maintaining a certain latency of avoidance responding, were combined, their compound produced a significantly shorter latency. It also appears that the latency to the compound is a function of the latency and per cent avoidance maintained by the single stimuli. For Ss 1-3, latencies were low and per cent avoidance was high, and the latency to the compound was reliably and significantly shorter. However, for S 4 , latency to both single stimuli was high and per cent avoidance was low, and the latency to the compound was neither reliably nor significantly shorter. S 5, which never learned to avoid at all to either stimulus, also never avoided to the compound.

These results are consistent with results reported by Miller (1969). A light and tone were established as preaversive stimuli which suppressed the rate of a leverpressing response. The compound of these single stimuli suppressèd responding even further. Furthermore, a compound composed of two highly suppressive stimuli suppressed responding more than did a compound of two less suppressive stimuli.

\section{REFERENCES}

GRINGS, W.M., \& O'DONNELL, D. E. Magnitude of response to compounds of discriminated stimuli. Journal of Experimental Psy chology, 1956, 52, 354-359.

HULL, C. L. Explorations in the patteming of stimuli conditioned to the G.S.R. Journal of Experimental Psychology, 1940, 27, 95-110.

MILLER, L. Compounding of pre-aversive stimuli. Journal of the Experimental Analysis of Behavior, 1969, 12, 293-299.

WEISS, S. J. Summation of response strengths instrumentally conditioned to stimuli in different sensory modalities. Joumal of Experimental Psy chology, 1964, 68, 15 1-155.

WOLF, M. M. Some effects of combined $\mathrm{SD}_{\mathrm{s}}$. Journal of the Experimental Analysis of Behavior, 1963, 6, 343-347.

\section{NOTE}

1. The author would like to extend his appreciation to the following people for their help in running the experiment: Bruce Caldwell, Markida Hipkins, Martin Lobdell, Catherine Nielsen, Fred Sundquist, and Linda Yanda. 